This is a self-archived version of an original article. This version may differ from the original in pagination and typographic details.

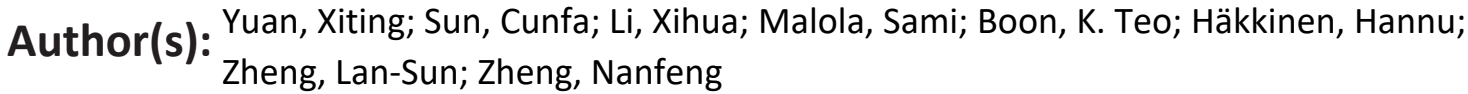

Title: Combinatorial Identification of Hydrides in a Ligated Ag40 Nanocluster with Noncompact Metal Core

Year: 2019

Version: Accepted version (Final draft)

Copyright: @ 2019 American Chemical Society

Rights: In Copyright

Rights url: http://rightsstatements.org/page/InC/1.0/?language=en

Please cite the original version:

Yuan, X., Sun, C., Li, X., Malola, S., Boon, K. T., Häkkinen, H., Zheng, L.-S., \& Zheng, N. (2019).

Combinatorial Identification of Hydrides in a Ligated Ag40 Nanocluster with Non-compact Metal Core. Journal of the American Chemical Society, 141(30), 11905-11911.

https://doi.org/10.1021/jacs.9b03009 


\title{
Article
}

\section{Combinatorial Identification of Hydrides in a Ligated Ag40 Nanocluster with Non-compact Metal Core}

\author{
Xiting Yuan, Cunfa Sun, Xihua Li, Sami Malola, Boon K
}

Teo, Hannu Häkkinen, Lan-Sun Zheng, and Nanfeng Zheng

J. Am. Chem. Soc., Just Accepted Manuscript • DOI: 10.1021/jacs.9b03009 • Publication Date (Web): 11 Jul 2019

Downloaded from pubs.acs.org on July 15, 2019

\section{Just Accepted}

"Just Accepted" manuscripts have been peer-reviewed and accepted for publication. They are posted online prior to technical editing, formatting for publication and author proofing. The American Chemical Society provides "Just Accepted" as a service to the research community to expedite the dissemination of scientific material as soon as possible after acceptance. "Just Accepted" manuscripts appear in full in PDF format accompanied by an HTML abstract. "Just Accepted" manuscripts have been fully peer reviewed, but should not be considered the official version of record. They are citable by the Digital Object Identifier (DOI®). "Just Accepted" is an optional service offered to authors. Therefore, the "Just Accepted" Web site may not include all articles that will be published in the journal. After a manuscript is technically edited and formatted, it will be removed from the "Just Accepted" Web site and published as an ASAP article. Note that technical editing may introduce minor changes to the manuscript text and/or graphics which could affect content, and all legal disclaimers and ethical guidelines that apply to the journal pertain. ACS cannot be held responsible for errors or consequences arising from the use of information contained in these "Just Accepted" manuscripts. 


\title{
Combinatorial Identification of Hydrides in a Ligated $\mathbf{A g}_{40}$ Nanocluster with Non-compact Metal Core
}

\author{
Xiting Yuan, ${ }^{1}$ Cunfa Sun, ${ }^{1}$ Xihua Li, ${ }^{1}$ Sami Malola, ${ }^{2}$ Boon K Teo, ${ }^{1}$ Hannu Häkkinen, ${ }^{*, 2}$ Lan-Sun Zheng, ${ }^{1}$ \\ Nanfeng Zheng*,1 \\ ${ }^{1}$ Collaborative Innovation Center of Chemistry for Energy Materials, State Key Laboratory for Physical Chemistry of Solid \\ Surfaces, and Department of Chemistry, National \& Local Joint Engineering Research Center of Preparation Technology of \\ Nanomaterials, College of Chemistry and Chemical Engineering, Xiamen University, Xiamen 361005, China \\ ${ }^{2}$ Departments of Physics and Chemistry, Nanoscience Center, University of Jyväskylä, FI-40014 Jyväskylä, Finland
}

KEYWORDS. Silver, metal hydride, metal nanocluster, coinage metal

ABSTRACT: No formation of bulk silver hydride has been reported. Until very recently, only few silver nanoclusters containing hydrides have been successfully prepared. However, due to the lack of effective techniques and also poor stability of hydridecontaining $\mathrm{Ag}$ nanoclusters, the identification of hydrides' location within $\mathrm{Ag}$ nanoclusters is challenging and not yet achieved although some successes have been reported on clusters of several $\mathrm{Ag}$ atoms. In this work, we report a detailed structural and spectroscopic characterization of the $\left[\mathrm{Ag}_{40}(\mathrm{DMBT})_{24}\left(\mathrm{PPh}_{3}\right)_{8} \mathrm{H}_{12}\right]^{2+}\left(\mathrm{Ag}_{40} \mathrm{H}_{12}\right)$ cluster (DMBT=2,4-dimethylbenzenethiol). The metal framework consists of three-concentric shells of $\mathrm{Ag}_{8} @ \mathrm{Ag}_{24} @ \mathrm{Ag}_{8}$ which can be described as ( $v_{1}$-cube)@(truncated- $v_{3}-$ octahedron)@(v2-cube), respectively. The presence of twelve hydrides in each cluster was systematically identified by various techniques. Based on a detailed analysis of the structural features and ${ }^{1} \mathrm{H}$ and ${ }^{2} \mathrm{H}$ NMR spectra, the positions of the 12 hydrides were determined to be residing on the 12 edges of the cubic core. As a result, the electron count of the $\mathrm{Ag}_{40}$ cluster is a two-electron superatomic system instead of a fourteen-electron system. Moreover, based on our DFT calculations and experimental probes, it was demonstrated that the 12 hydrides play a crucial role in stabilizing both the electronic and geometric structure of the $\mathrm{Ag}_{40} \mathrm{H}_{12}$ cluster. The successful synthesis of stable hydride-containing Ag nanoclusters and the identification of hydride positions are expected to simulate research attention on both synthesis and application of hydride-containing Ag nanomaterials.

\section{INTRODUCTION}

Nanoclusters are known as molecular nanoparticles. Because of their specific structures, unique optical absorption, physicochemical and electronic properties, metal nanoclusters have attracted much research attention in the past decade. ${ }^{1-4}$ These properties enable their potential applications in many fields including catalysis, ${ }^{5-6}$ bio-sensing and bio-imaging, etc. ${ }^{7-}$ ${ }^{8}$ In the long history of nanoclusters, especially ligand-protected $\mathrm{Au}$ and $\mathrm{Ag}$ nanoclusters have been widely investigated. ${ }^{1}$ Organic ligands like thiols, ${ }^{9}$ phosphines, ${ }^{10}$ and their combinations ${ }^{11}$ are usually used in the classic solution synthesis of metal nanocluster. These ligands are developed to stabilize a large number of clusters, gold clusters like $\mathrm{Au}_{21},{ }^{12} \mathrm{Au}_{25},{ }^{13}$ $\mathrm{Au}_{102}{ }^{14} \mathrm{Au}_{144}{ }^{15}$ and silver clusters like $\mathrm{Ag}_{14},{ }^{16} \mathrm{Ag}_{25},{ }^{17} \mathrm{Ag}_{29},{ }^{18}$ $\mathrm{Ag}_{44},{ }^{9}$ and alloy clusters like $\mathrm{Au}_{12} \mathrm{Ag}_{32}$. The stabilizing effect of small ligands (e.g., $\left.\mathrm{H}^{-}\right)$was rarely investigated in the field of metal nanoclusters. However, small inorganic ligands have been demonstrated as effective ligands to facilitate the charge transport between individual nanocrystals. ${ }^{19}$ Also it is wellknown that the metal hydride is a key intermediate to proceed the reaction. ${ }^{20}$ More research attention should thus be directed towards the hydride chemistry of coinage metal nanoclusters.

High-nuclearity $\mathrm{Cu}$ hydride clusters are more common while $\mathrm{Ag}$ hydride clusters are relatively rare. ${ }^{21}$ Some nice highnuclearity $\mathrm{Cu}$ hydride clusters, such as $\left[\mathrm{Cu}_{20}(\mathrm{H})_{11}\left\{\mathrm{R}_{2} \mathrm{P}(\mathrm{O} i \mathrm{Pr})_{2}\right\}_{9}\right]$ $(\mathrm{R}=\mathrm{S}, \quad \mathrm{Se}),{ }^{22} \quad\left[\mathrm{Cu}_{28}(\mathrm{H})_{15}\left\{\mathrm{~S}_{2} \mathrm{CNPr}_{2}\right\}_{12}\right] \mathrm{PF}_{6},{ }^{23}$ $\left[\mathrm{Cu}_{32}(\mathrm{H})_{20}\left\{\mathrm{~S}_{2} \mathrm{P}(\mathrm{O} i \mathrm{Pr})_{2}\right\}_{12}\right]^{24}$ and $\left[\mathrm{Cu}_{25} \mathrm{H}_{10}\left(\mathrm{SPhCl}_{2}\right)_{18}\right]^{3-, 25}$ have been reported by Liu and coworkers. In comparison, reports on $\mathrm{Ag}$ hydride clusters are rather limited to small-nuclearity clusters. Some examples are $\left[\mathrm{Ag}_{3}\left\{\left(\mathrm{PPh}_{2}\right)_{2} \mathrm{CH}_{2}\right\}_{3}(\mathrm{H}) \mathrm{Cl}\right] \mathrm{BF}_{4}$, $\left[\mathrm{Ag}_{3}(\mathrm{H})\left(\mathrm{BH}_{4}\right) \mathrm{L}_{3}^{\mathrm{Ph}}\right]\left(\mathrm{BF}_{4}\right) \quad\left(\mathrm{L}^{\mathrm{Ph}}=\right.$ bis(diphenylphosphino)amine), $\left[\left\{\mathrm{Ag}_{7}(\mathrm{H})\left(\mathrm{E}_{2} \mathrm{P}(\mathrm{OR})_{2}\right\}_{6}\right],\left[\mathrm{Ag}_{11}(\mathrm{H})\left(\mathrm{S}_{2} \mathrm{P}(\mathrm{OEt})_{2}\right)_{9}\right]^{+}(\mathrm{R}=i \mathrm{Pr}, \mathrm{E}=\mathrm{Se}\right.$; $\mathrm{R}=\mathrm{Et}, \quad \mathrm{E}=\mathrm{S}), \quad\left[\mathrm{Ag}_{6} \mathrm{H}_{4}(\mathrm{dppm})_{4}(\mathrm{OAc})_{2}\right] \quad(\mathrm{dppm}=1,1-$ bis(diphenylphosphino)methane) and $\left[\mathrm{Ag}_{8}(\mathrm{H})\left\{\mathrm{Se}_{2} \mathrm{P}(\mathrm{OR})_{2}\right\}_{6}\right]^{+}$ $(\mathrm{R}=\mathrm{iPr} ; \mathrm{Et}){ }^{26-33} \mathrm{In} 2016$, Bakr's group reported a new class of high-nuclearity silver hydride nanoclusters: $\left[\mathrm{Ag}_{18} \mathrm{H}_{16}(\mathrm{TPP})_{10}\right]^{2+}$ (TPP=triphenylphosphine), $\left[\mathrm{Ag}_{25} \mathrm{H}_{22}(\mathrm{DPPE})_{8}\right]^{3+} \quad(\mathrm{DPPE}=1,2-$ bis(diphenylphosphino)ethane) and $\left.\left[\mathrm{Ag}_{26} \mathrm{H}_{22} \text { (TFPP) }\right)_{13}\right]^{2+}$ (TFPP= tris(4-fluorophenyl)phosphine), which were merely confirmed by ESI-MS and UV-vis spectra. ${ }^{21}$ However, their total structures have not been resolved yet. The identification of hydrides within metal clusters is challenging. The neutron diffraction is definitely the top choice to unequivocally determine the location of hydrides. ${ }^{34}$ But it has rarely been done for silver and copper hydride clusters probably because of the requirement of growing large single crystals for neutron diffraction which is also not easily available. In 2013, O'Hair and coworkers reported their success in determining the position of hydrides in $\left[\mathrm{Ag}_{3}\left\{\left(\mathrm{PPh}_{2}\right)_{2} \mathrm{CH}_{2}\right\}_{3}(\mathrm{H}) \mathrm{Cl}\right] \mathrm{BF}_{4}$ cluster using neutron diffraction. ${ }^{35}$ While challenging, it is also possible to use X-ray diffraction to determine the positions of hydrides within metal clusters because of the presence of two electrons on each hydride and also the difference in bond lengths of M-H-M and M-M. ${ }^{25,34}$ 
Of particular interest in terms of high-nuclearity hydride-rich Ag clusters are two recent reports on $\mathrm{Ag}_{40}$ clusters protected by thiolate and phosphine ligands. ${ }^{36-37}\left[\mathrm{Ag}_{40}(\mathrm{DMBT})_{24}\left(\mathrm{PPh}_{3}\right)_{8}\right]$ (hereafter abbreviated as $\mathrm{Ag}_{40}$ ) where DMBT $=2,4-$ dimethylbenzenethiol. These recent publications prompted us to report our independent synthesis and structure of a hydriderich thiolated silver nanocluster, characterized by us as $\left[\mathrm{Ag}_{40}(\mathrm{DMBT})_{24}\left(\mathrm{PPh}_{3}\right)_{8} \mathrm{H}_{12}\right]^{2+} \quad$ (hereafter abbreviated as $\mathrm{Ag}_{40} \mathrm{H}_{12}$ ). The electron counting rule ${ }^{38}$ suggests that the $\mathrm{Ag}_{40} \mathrm{H}_{12}$ cluster is a two-electron superatomic system, ${ }^{39}$ rather than a 14/16-electron system of $\left[\mathrm{Ag}_{40}(\mathrm{DMBT})_{24}\left(\mathrm{PPh}_{3}\right)_{8}\right]\left(\mathrm{Ag}_{40}\right)$ as advocated by others. The detailed comparison of the three $\mathrm{Ag}_{40}$ clusters is presented in Table S1. The contrast of the results of the present study with those reported by others demonstrates the importance to combine different techniques to reveal the true identity of Ag nanoclusters. ${ }^{40}$

\section{RESULTS AND DISCUSSION}
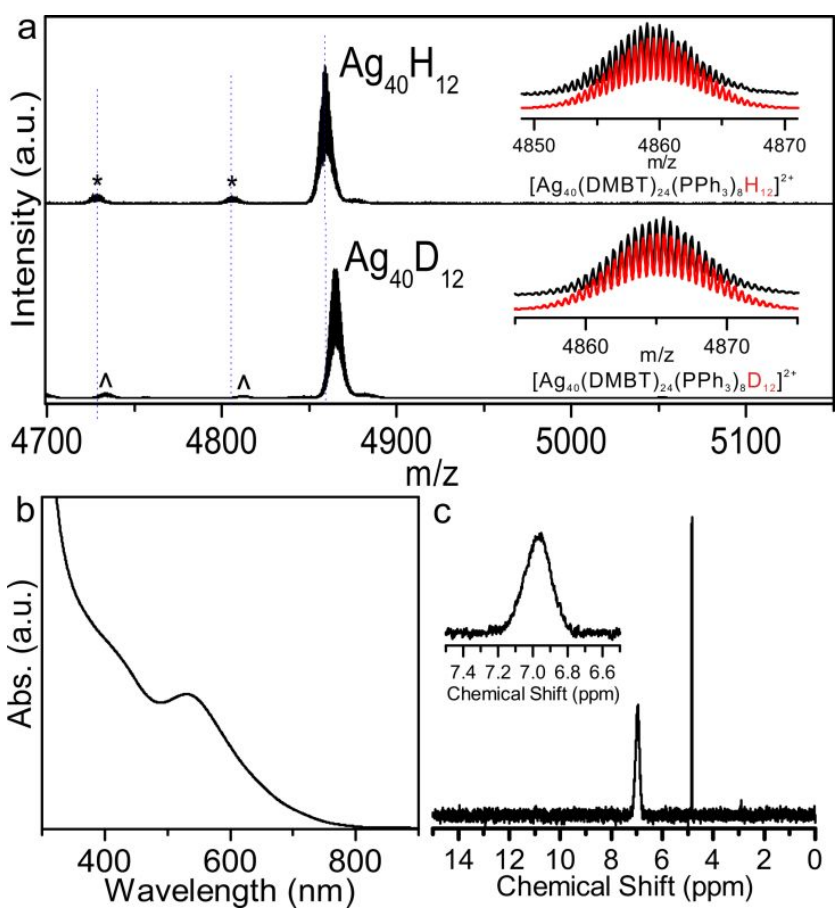

Figure 1. ESI-MS and UV-vis spectra for $\mathrm{Ag}_{40}(\mathrm{H} / \mathrm{D})_{12}$ clusters. (a) ESI-MS spectra for $\mathrm{Ag}_{40} \mathrm{H}_{12}$ and $\mathrm{Ag}_{40} \mathrm{D}_{12}$ clusters in the positive mode in $\mathrm{CH}_{2} \mathrm{Cl}_{2} / \mathrm{CH}_{3} \mathrm{OH}$ (4:1). From right to left: ${ }^{*} \mathrm{Ag}_{40} \mathrm{H}_{12}-\mathrm{PPh}_{3}$, $\mathrm{Ag}_{40} \mathrm{H}_{12}-2 \mathrm{PPh}_{3}, \wedge \mathrm{Ag}_{40} \mathrm{D}_{12}-\mathrm{PPh}_{3}, \mathrm{Ag}_{40} \mathrm{D}_{12}-2 \mathrm{PPh}_{3}$; Inset: simulated (red curve) and experimental (black curve) isotope distribution patterns. (b) UV-vis spectrum of pure $\left[\mathrm{Ag}_{40}(\mathrm{DMBT})_{24}\left(\mathrm{PPh}_{3}\right)_{8} \mathrm{H}_{12}\right]^{2+}$ crystals dissolved in $\mathrm{CH}_{2} \mathrm{Cl}_{2} / \mathrm{CH}_{3} \mathrm{OH}$. (c) ${ }^{2} \mathrm{H}$ NMR spectrum for pure $\mathrm{Ag}_{40} \mathrm{D}_{12}$ cluster. (Solvent $\mathrm{CD}_{2} \mathrm{Cl}_{2}$ peak at $4.85 \mathrm{ppm})$.

Synthesis and Characterizations of Clusters $\operatorname{Ag}_{40} D_{12}$ and $\mathbf{A g}_{40} \mathbf{H}_{12}$. In a typical synthesis of $\mathrm{Ag}_{40} \mathrm{H}_{12}$, silver acetate was dispersed in a 1:1 mixture of $\mathrm{CH}_{3} \mathrm{OH}$ and $\mathrm{CH}_{2} \mathrm{Cl}_{2}$. The solution was cooled to $0{ }^{\circ} \mathrm{C}$ in an ice bath. Then 2,4-DMBT and $\mathrm{PPh}_{3}$ were added to the mixture under vigorous stirring. After further stirring for 15 minutes, an aqueous solution of $\mathrm{NaBH}_{4}$ was added dropwise. The reaction mixture was stirred for 3 hours in the ice bath. Then an aqueous solution of $\mathrm{KPF}_{6}$ was added. After being stirred for one more hour, the dark brown-red solution was washed with water and methanol and subjected to electrospray ionization mass spectrometry (ESI-MS) measurements. While a major peak at $\sim 4860$ was clearly observed in the positive mode, no obvious peaks were observed in the negative mode. While the major peak at $\sim 4860$, shown in Figure 1a, was identified as $\left[\mathrm{Ag}_{40}(\mathrm{SR})_{24}\left(\mathrm{PPh}_{3}\right)_{8} \mathrm{H}_{12}\right]^{2+}$, a minor peak at $\sim 3239$ was attributed to $\left[\mathrm{Ag}_{40}(\mathrm{SR})_{24}\left(\mathrm{PPh}_{3}\right)_{8} \mathrm{H}_{13}\right]^{3+}$ (Figure S1). Two weak peaks at 4805 and 4727 were assigned to $\left[\mathrm{Ag}_{40}(\mathrm{SR})_{24}\left(\mathrm{PPh}_{3}\right)_{7} \mathrm{H}_{12}\right]^{2+}$ and $\left[\mathrm{Ag}_{40}(\mathrm{SR})_{24}\left(\mathrm{PPh}_{3}\right)_{6} \mathrm{H}_{12}\right]^{2+}$, respectively. The most surprising feature of the MS result is the discovery of the 12 hydrides in the cluster. To further corroborate this finding, we prepared the deuteride analog, namely, $\left[\mathrm{Ag}_{40}(\mathrm{DMBT})_{24}\left(\mathrm{PPh}_{3}\right)_{8} \mathrm{D}_{12}\right]^{2+}$ (hereafter abbreviated as $\mathrm{Ag}_{40} \mathrm{D}_{12}$ ) by using $\mathrm{NaBD}_{4}$ instead of $\mathrm{NaBH}_{4}$ as the reductant for the synthesis of the clusters. As shown in Figure 1a, there was an increase of exactly 6 daltons for the $\left[\mathrm{Ag}_{40}(\mathrm{SR})_{24}\left(\mathrm{PPh}_{3}\right)_{8} \mathrm{H}_{12}\right]^{2+}$ peak as expected. It should be pointed out that the $\left[\mathrm{Ag}_{40}(\mathrm{SR})_{24}\left(\mathrm{PPh}_{3}\right)_{8} \mathrm{D}_{12} \mathrm{H}\right]^{3+}$ peak was observed as the major ESMS peak for the $\mathrm{Ag}_{40} \mathrm{D}_{12}$ sample. High-resolution Fourier transform ion cyclotron resonance-mass spectrometry (FTICRMS) data confirmed the presence of $12 \mathrm{D}$ in the $\mathrm{Ag}_{40} \mathrm{D}_{12}$ cluster (Figure S1f).

Figure $1 \mathrm{~b}$ shows the UV-vis spectrum of $\mathrm{Ag}_{40} \mathrm{H}_{12}$ crystals dissolved in $\mathrm{CH}_{2} \mathrm{Cl}_{2} / \mathrm{CH}_{3} \mathrm{OH}$. Two absorption features were observed: one peak at $530 \mathrm{~nm}$, and a shoulder at $416 \mathrm{~nm}$. We also recorded the ${ }^{2} \mathrm{H}$ NMR spectra of $\mathrm{Ag}_{40} \mathrm{D}_{12}$ in $\mathrm{CH}_{2} \mathrm{Cl}_{2}$ and that of $\mathrm{Ag}_{40} \mathrm{H}_{12}$ in $\mathrm{CD}_{3} \mathrm{OD}$ separately. The 12 deuterides display a signal centered at $6.95 \mathrm{ppm}$ in ${ }^{2} \mathrm{H}$ NMR spectrum (Figure 1c) corresponding to a signal at $6.55 \mathrm{ppm}$ in the ${ }^{1} \mathrm{H}$ NMR spectrum of $\mathrm{Ag}_{40} \mathrm{H}_{12}$ (Figure $\mathrm{S} 2$ ). The unresolved broad peaks suggested that the 12 hydrides are in the similar chemical environment.

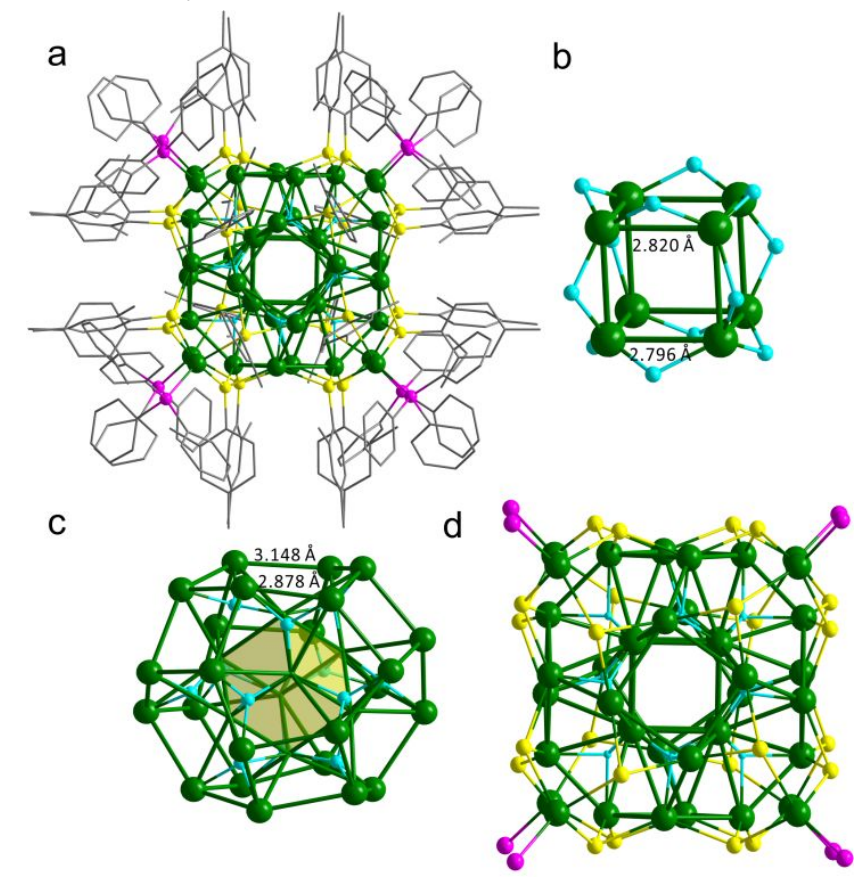

Figure 2. Molecular structure of the $\left[\mathrm{Ag}_{40}(\mathrm{DMBT})_{24}\left(\mathrm{PPh}_{3}\right)_{8} \mathrm{H}_{12}\right]^{2+}$ cluster resolved by X-ray single crystal analysis. (a) Total structure of $\mathrm{Ag}_{40} \mathrm{H}_{12}$ cluster without hydrogen atoms on the ligands; (b) The innermost shell of the cluster with hydrides; (c) The core shell of the cluster with hydrogen atoms; (d) The total structure of the cluster with carbon and hydrogen atoms in the ligand shell omitted for clarity. Colors: Ag, green; $\mathrm{H}$ in the core, cyan; S, yellow; $\mathrm{P}$, pink; C, grey. 
Molecular Structure of $\mathbf{A g}_{40} \mathrm{H}_{12}$ and its Hydride Positions. Cube-like black-red crystals were obtained after about two weeks by layering hexane onto a $\mathrm{CH}_{2} \mathrm{Cl}_{2}$ solution at $4{ }^{\circ} \mathrm{C}$. The molecular structure of the $\mathrm{Ag}_{40} \mathrm{H}_{12}$ cluster was determined by single-crystal X-ray crystallography at $100 \mathrm{~K}$. The hydride positions were determined from peaks in the difference electron density map of the crystallographic data, and their coordinates were successfully least-squares refined. ${ }^{41-42}$ As shown in Figures 2a-d, the $\mathrm{Ag}_{40} \mathrm{H}_{12}$ cluster consists of three-concentric shells of $\mathrm{Ag}_{8} @ \mathrm{Ag}_{24} @ \mathrm{Ag}_{8} \quad$ corresponding to ( $v_{1}$-cube) @(truncated- $v_{3}$-octahedron)@(v

As shown in Figure 2b, the core is a simple cube ( $v_{1}$-cube) of $8 \mathrm{Ag}$ atoms with an average $\mathrm{Ag}-\mathrm{Ag}$ distance of $2.806 \AA$. At roughly the midpoints of the 12 edges of the $\mathrm{Ag}_{8}$ cube resided the 12 hydrides. These four-coordinate $\left(\mu_{4}-\mathrm{H}\right)$ hydrides lie in the centers of the tetrahedra with $\mathrm{Ag}-\mathrm{H}$ distances in the range from 1.686 to $2.147 \AA$ (Figure S3) which is similar to those reported for $\mu_{4}-\mathrm{H}$ in the literature. ${ }^{26-27,}{ }^{29}$ Figure $2 \mathrm{c}$ depicts the second shell which is a distorted truncated- $v_{3}$-octahedron $\left(\mathrm{T}_{3} \mathrm{O}\right)$ of $24 \mathrm{Ag}$ atoms. The truncated octahedron shell has eight hexagon and six square faces. There are two sets of Ag-Ag distances within each hexagon face. Those neighboring hexagons have an average bond distance of $2.878 \AA$, significantly shorter than that of $3.148 \AA$ of those neighboring square faces. This disparity is significant for the following reason. As it turns out, the 12 interstitial hydrides are nested in the tetrahedral cavities formed by one edge of the inner cube and one edge of the $\mathrm{T}_{3} \mathrm{O}$. The short Ag-Ag bonds within the core and within the $\mathrm{T}_{3} \mathrm{O}$ shell suggest there is a strong interaction between the hydrides and their tetrahedral hosts, as well among the host Ag atoms themselves. For completeness, the other four Ag-Ag bonds of the tetrahedral host have an average distance of $3.197 \AA$ (Figure S3). The latter represent the average distance between the cubic core and the $\mathrm{T}_{3} \mathrm{O}$ shell (Table S3). We note that similar phenomenon had been observed in $\left[\mathrm{Cu}_{28}(\mathrm{H})_{15}\left(\mathrm{~S}_{2} \mathrm{CNR}\right)_{12}\right] \mathrm{PF}_{6}\left(\mathrm{NR}=\mathrm{N}^{\mathrm{n}} \mathrm{Pr}_{2}\right.$ or aza-15crown-5) cluster, ${ }^{23}$ for example.

Finally, Figure $2 \mathrm{~d}$ portrays the total structure of $\mathrm{Ag}_{40} \mathrm{H}_{12}$ without the phenyl groups. The eight $\mathrm{AgS}_{3} \mathrm{P}$ units fashion tetrahedrally coordinated $\mathrm{Ag}$ atoms which cap the 8 hexagonal faces of the $\mathrm{T}_{3} \mathrm{O}$ shell via three bridging thiolates, giving rise to the surface $\mathrm{Ag}_{8} \mathrm{~S}_{24} \mathrm{P}_{8}$ shell. The outer eight $\mathrm{Ag}$ atoms in the surface shell, each bearing a phosphine ligand, also form a simple $v_{3}$-cube with $\mathrm{Ag} \cdots \mathrm{Ag}$ distances averaging $7.852 \AA$. The packing of $\mathrm{Ag}_{40}$ cluster is shown in SI (Figure S4 and S5).

Critical role of hydrides revealed by computational results. The role of the hydrides was also investigated by density functional theory (DFT) calculations using the GPAW software. ${ }^{43}$ In particular, the electronic structure and dynamic stability of the $\mathrm{Ag}_{40} \mathrm{H}_{12}$ cluster were explored (see technical details in the experimental session). Starting from the crystal structure, the $\left[\mathrm{Ag}_{40}(\mathrm{DMBT})_{24}\left(\mathrm{PPh}_{3}\right)_{8} \mathrm{H}_{12}\right]^{2+}$ cluster was relaxed to its nearest local energy minimum, where the important atomatom distances match well with the experimental data.

The analysis of the frontier orbitals, shown in Figure S6, gives a definite support for the interpretation of the hydrogens found in the silver core as hydrides. The cluster has a large HOMO-LUMO energy gap of $1.42 \mathrm{eV}$ indicating high electronic stability, with the HOMO orbital having an S-type symmetry $\left(\mathrm{A}_{\mathrm{g}}\right.$ if projected to the $\mathrm{O}_{\mathrm{h}}$ point group, ${ }^{44}$ Figure $\mathrm{S} 6 \mathrm{a}$, b) as would be expected from a two-electron superatom of the silver-hydride cluster as per the well-known Jellium model. The analysis of the atomic charges by the Bader method (Table S2) also shows that the hydrogens are considerably negatively charged by an average of -0.2 unit charge per $\mathrm{H}$, affecting the charge of the inner $\mathrm{Ag}_{8}+\mathrm{Ag}_{24}$ shells. The negatively charged hydrogen atoms corroborate their characterization as hydrides. For reference, we also optimized the cluster after removing the 12 hydrogens from the structure to form the $\mathrm{Ag}_{40}$ cluster. The cluster has a much smaller HOMO-LUMO gap $(0.32 \mathrm{eV})$. It has a split D-symmetric configuration of 10 electrons around the gap as shown in Figure S6c. Projecting these states to the $\mathrm{O}_{h}$ symmetry group shows that the states are split as $\mathrm{T}_{2 \mathrm{~g}}(4+2)$ and $\mathrm{E}_{\mathrm{g}}(4)$ with the 6 electrons in the $\mathrm{T}_{2 \mathrm{~g}}$ being the occupied states just below the HOMO-LUMO gap (Figure S6d). a

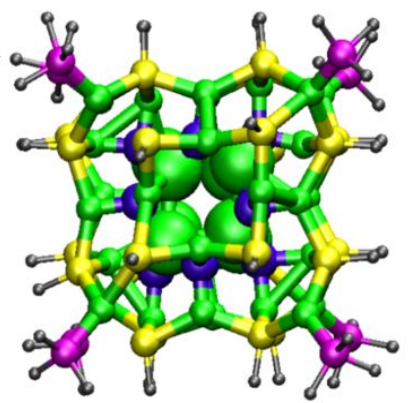

C

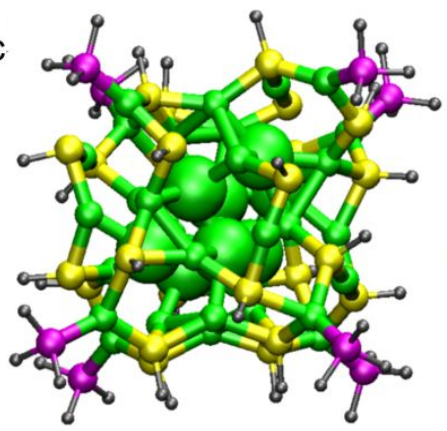

b

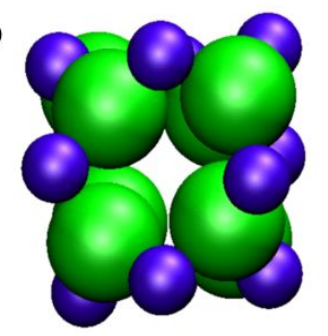

Figure 3. Snapshots from the last respective time steps (after about $1.2 \mathrm{ps})$ of the MD runs of $(\mathrm{a}, \mathrm{b})\left[\mathrm{Ag}_{40} \mathrm{H}_{12}\left(\mathrm{PR}_{3}\right)_{8}(\mathrm{SR})_{24}\right]^{2+}$ and $(\mathrm{c}, \mathrm{d})$ $\left[\mathrm{Ag}_{40}\left(\mathrm{PR}_{3}\right)_{8}(\mathrm{SR})_{24}\right]^{2+}$ clusters with simplified ligands $\mathrm{P}\left(\mathrm{CH}_{3}\right)_{3}$ and $\mathrm{SCH}_{3}$. a and $\mathrm{c}$ show the full cluster and $\mathrm{b}, \mathrm{d}$ highlight the inner 8 Ag atoms. Colors: Ag: green; $\mathrm{H}$ in the core: purple; $\mathrm{S}$ : yellow; $\mathrm{P}$ : pink; C: grey. Hydrogens in the ligand shell are omitted for clarity.

Moreover, although the cluster without hydrides found a locally stable energy minimum, it is not a dynamically stable structure. To check the dynamic stability, we performed molecular dynamics (MD) simulations for cluster models of $\mathrm{Ag}_{40} \mathrm{H}_{12}$ and $\mathrm{Ag}_{40}$ clusters with a simplified ligand layer (by replacing 2,4-DMBT with $\mathrm{SCH}_{3}$ and $\mathrm{PPh}_{3}$ by $\left.\mathrm{P}\left(\mathrm{CH}_{3}\right)_{3}\right)$. During a rather short MD run of about 1.2 ps ( $\sim 600$ time steps), the silver core of the cluster without 12 hydrides immediately and permanently distorted away from the initial $\mathrm{O}_{\mathrm{h}}$ symmetry while the $\mathrm{Ag}_{40} \mathrm{H}_{12}$ cluster thermally vibrated around the initial crystal structure, see Figure 3 and the two animation videos in the SI material. This result re-confirms that the 14-electron $\left[\mathrm{Ag}_{40}(\mathrm{SR})_{24}\left(\mathrm{PR}_{3}\right)_{8}\right]^{2+}$ cluster without hydrides should not be found in the observed crystal structure. The 12 hydrides play a crucial role in stabilizing the $\left[\mathrm{Ag}_{40}(\mathrm{DMBT})_{24}\left(\mathrm{PPh}_{3}\right)_{8} \mathrm{H}_{12}\right]^{2+}$ cluster and in maintaining the $\mathrm{O}_{\mathrm{h}}$ symmetry.

Stability of $\mathbf{A g}_{40} \mathbf{D}_{12}$ Clusters in Solution. To explore the dynamics suggested by the above-mentioned theoretical calculations, we performed an in-situ variable temperature 
study of UV-vis (Figure S8), ESI-MS (Figure 4a and S9) and ${ }^{2} \mathrm{H}$ NMR spectra (Figure S10) of $\mathrm{Ag}_{40} \mathrm{D}_{12}$. Crystals of $\mathrm{Ag}_{40} \mathrm{D}_{12}$ were dissolved in $\mathrm{CH}_{2} \mathrm{Cl}_{2}: \mathrm{CH}_{3} \mathrm{OH}$ for the temperaturedependent measurements. The temperature was ramped to the desired temperature by every $10^{\circ} \mathrm{C}$ in $8 \mathrm{~min}$ to assure that limited change took place during the temperature ramping process. As shown in Figure $4 \mathrm{a}$ and S8, the ESI-MS spectra measured at the temperature ranging from 10 to $90^{\circ} \mathrm{C}$ all display a major peak at $\sim 3244$, corresponding to the $3+$ ion of $\operatorname{Ag}_{40} D_{12}$ (highlighted in box) with detachment of one $\mathrm{PPh}_{3}$ and attachment of a proton. The $\mathrm{Ag}_{40} \mathrm{D}_{12}$ cluster was stable up to 40 ${ }^{\circ} \mathrm{C}$ with appearance of new peaks within $24 \mathrm{~min}$. Starting from $50{ }^{\circ} \mathrm{C}$, there was a slow decrease at the peak of $\sim 3244$ with the simultaneous appearance of a set of peals at $\sim 2437$. According to the isotope pattern analysis (Figure S11), this set of peaks at 2437 can be assigned to $\left[\mathrm{Ag}_{15}(\mathrm{DMBT})_{6}\left(\mathrm{PPh}_{3}\right)_{9-\mathrm{x}} \mathrm{Cl}_{2} \mathrm{H}\right]^{2+}$ with $\mathrm{x}$ $=0$-2. the analysis also revealed the presence of trace amounts of $\left[\mathrm{Ag}_{15}(\mathrm{DMBT})_{8}\left(\mathrm{PPh}_{3}\right)_{8} \mathrm{Cl}_{3}\right]^{2+},\left[\mathrm{Ag}_{16}(\mathrm{DMBT})_{7}\left(\mathrm{PPh}_{3}\right)_{9} \mathrm{Cl}_{2} \mathrm{H}\right]^{2+}$, $\left[\mathrm{Ag}_{16}(\mathrm{DMBT})_{7}\left(\mathrm{PPh}_{3}\right)_{10} \mathrm{Cl}_{3}\right]^{2+}$, and $\left[\mathrm{Ag}_{23}(\mathrm{DMBT})_{14}\left(\mathrm{PPh}_{3}\right)_{8} \mathrm{Cl}_{2} \mathrm{D}_{3} \mathrm{H}_{2}\right]^{2+}$ clusters containing both $\operatorname{Ag}(0)$ and $\operatorname{Ag}(\mathrm{I})$.

The deuterides in $\mathrm{Ag}_{40} \mathrm{D}_{12}$, as well as the hydrides in $\mathrm{Ag}_{40} \mathrm{H}_{12}$ are all situated between the innermost cubic core and the $\mathrm{T}_{3} \mathrm{O}$ shell, and are therefore more difficult to remove. By raising the temperature to $100{ }^{\circ} \mathrm{C}$, the $\mathrm{Ag}_{40} \mathrm{D}_{12}$ clusters were totally destroyed with the loss of deuterides. Together with the formation of silver mirror, the formation of small clusters like $\left[\mathrm{Ag}_{15}(\mathrm{DMBT})_{6}\left(\mathrm{PPh}_{3}\right)_{9-\mathrm{x}} \mathrm{Cl}_{2} \mathrm{H}\right]^{2+} \quad(\mathrm{x}=0-2)$ was observed (highlighted by dashed box). This confirms the DFT calculations that these 12 hydrides play a pivotal role in stabilizing the metal framework of the $\mathrm{Ag}_{40}$ cluster.

We also recorded the temperature-dependent UV-vis and ${ }^{2} \mathrm{H}$ NMR spectra to confirm the stability data provided by ESI-MS spectra. As show in Figure S8, the UV-vis spectra of the $\mathrm{Ag}_{40} \mathrm{D}_{12}$ cluster at 10 to $40{ }^{\circ} \mathrm{C}$ are quite similar. Further raising the temperature to $70^{\circ} \mathrm{C}$ led to a big jump in the absorption with a broad peak at $487 \mathrm{~nm}$, which can be attributed to the formation of plasmonic $\mathrm{Ag}$ nanoparticles. When heated above $80^{\circ} \mathrm{C}$, the absorbance decreased due to the formation of $\mathrm{Ag}$ mirror. Similarly, from the ${ }^{2} \mathrm{H}$ NMR spectra (Figure S10), the $\operatorname{Ag}_{40} \mathrm{D}_{12}$ cluster was stable to $40^{\circ} \mathrm{C}$. At $60^{\circ} \mathrm{C}$, a new signal at $4.02 \mathrm{ppm}$ was observed. This peak came from the dissolved $\mathrm{D}_{2}$, suggesting that the $\operatorname{Ag}_{40} \mathrm{D}_{12}$ clusters were already decomposed with the release of $\mathrm{D}_{2}$.

We also followed the ESI-MS spectra of $\mathrm{Ag}_{40} \mathrm{D}_{12}$ as a function of time to assess its stability at room temperature $\left(25^{\circ} \mathrm{C}\right)$ (Figure 4b). As shown in Figure 4b, no obvious change in the ESI-MS spectra of the cluster was detected in the first 4.5 hours. There was, however, an abrupt degradation of the major MS peak after 4.5 hours. The degradation continued until $26.5 \mathrm{~h}$ when the molecular peak of $\mathrm{Ag}_{40} \mathrm{D}_{12}$ practically disappeared, and some small clusters like $\left[\mathrm{Ag}_{9}(\mathrm{DMBT})_{3}\left(\mathrm{PPh}_{3}\right)_{6} \mathrm{ClD}_{7} \mathrm{H}_{2}\right]^{+}$at the peak of 3006 were formed in the solution. These results demonstrated that the hydride-stabilized Ag nanoclusters reported in this work exhibit a reasonably good stability in solutions, making them an interesting system for further investigating the hydride chemistry on metal nanoclusters.

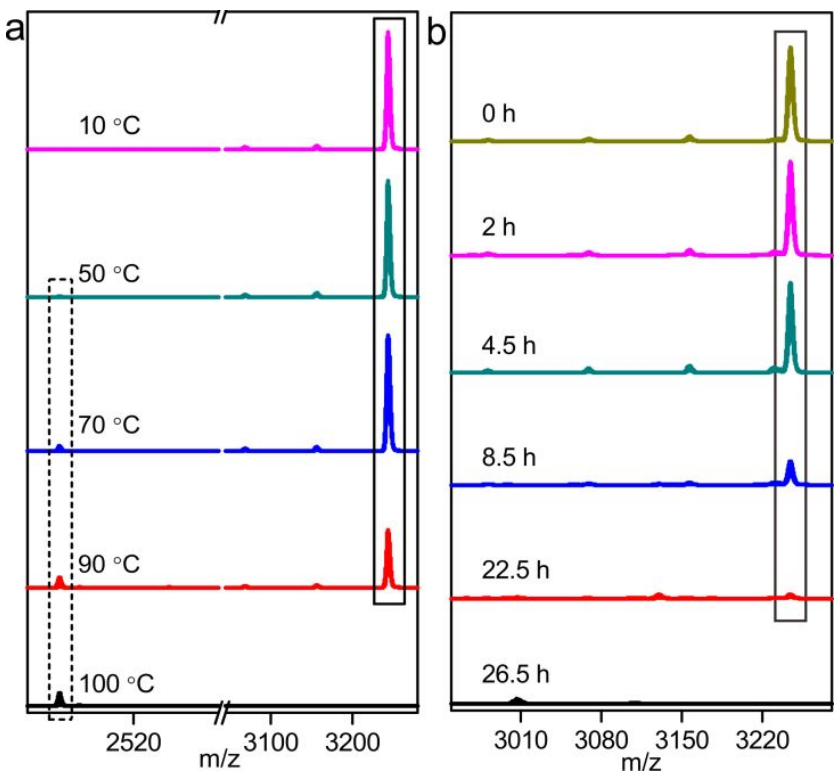

Figure 4. Temperature-depending and real-time tracking ESI-MS spectra of $\mathrm{Ag}_{40} \mathrm{D}_{12}$ cluster in room temperature in the mixed solvent of $\mathrm{CH}_{3} \mathrm{OH}$ and $\mathrm{CH}_{2} \mathrm{Cl}_{2}$ (1:1). (a) Temperature-depending ESI-MS spectra of $\mathrm{Ag}_{40} \mathrm{D}_{12}$ cluster in oil bath; (b) Real-time tracking ESIMS spectra for $\mathrm{Ag}_{40} \mathrm{D}_{12}$ cluster in room temperature $\left(25^{\circ} \mathrm{C}\right)$.

\section{CONCLUSION}

In conclusion, several combinatorial techniques have been used to identification of hydrides in a ligated $\mathrm{Ag}_{40}$ nanocluster with a non-compact metal core co-stabilized by thiolates and phosphines. The presence of 12 hydrides in each cluster was characterized by single-crystal analysis, and confirmed by ESIMS and ${ }^{1} \mathrm{H} /{ }^{2} \mathrm{H}$ NMR spectra. Based on our DFT calculations and experimental probes, the 12 hydrides play a crucial role in stabilizing the electronic and geometric structure of the cluster. Due to the challenges in characterizing hydrides in metal nanoclusters, deuterium labelling experiments are important and helpful to reveal the true identity of hydride-containing metal nanoclusters. We expect that our success in crystallizing the hydride-rich silver nanoclusters and deciphering the positions of hydrides is going to stimulate more research towards the controlled synthesis of hydride-rich silver nanoclusters and explorations of the hydride chemistry of these uncommon nanoclusters.

\section{EXPERIMENTAL SECTION}

Reagents. Silver acetate $\left(\mathrm{AgCH}_{3} \mathrm{COO}\right.$, purity 99.5\%), 2,4dimethylthiophenol (2,4-DMBT, purity $98 \%$ ) were purchased from Energy Chemical Reagent Co. Ltd (Shanghai, China). Sodium borodeuteride $\left(\mathrm{NaBD}_{4}\right.$, purity $98 \%$ ) was purchased from Sodium borohydride $\left(\mathrm{NaBH}_{4}\right.$, purity $98 \%$ ) was purchased from J\&k Reagent. Potassium hexafluorophosphate $\left(\mathrm{KPF}_{6}\right.$, purity $\left.99 \%\right)$ was purchased from Innochem Reagent (Beijing, China). Triphenylphosphine $\left(\mathrm{PPh}_{3}\right)$ and all solvents used in the study were purchased from Sinopharm Chemical Reagent Co. Ltd. (Shanghai, China). All reagents used in experiments were used as received without further purification. The water used was ultrapure.

Synthesis of $\left[\mathbf{A g}_{40}(\mathbf{2}, \mathbf{4}-\mathrm{DMBT})_{\mathbf{2 4}}\left(\mathbf{P P h}_{\mathbf{3}}\right)_{\mathbf{8}} \mathrm{H}_{12}\right] .100 \mathrm{mg}$ of $\mathrm{AgCH}_{3} \mathrm{COO}(0.6 \mathrm{mmol})$ was dissolved in the mixture of dichloromethane and methanol $(3: 1)$. The mixture was then cooled 
to $0{ }^{\circ} \mathrm{C}$ in an ice bath. After a $1 \mathrm{~mL}$ methanol solution of $40 \mu \mathrm{L} \mathrm{2,4-}$ Dimethylthiophenol (2,4-DMBT, $0.3 \mathrm{mmol})$ and $100 \mathrm{mg}$ triphenylphosphine $(0.38 \mathrm{mmol})$ was introduced into the mixture under vigorous stirring. After 15 minutes stirring, $30 \mathrm{mg} \mathrm{NaBH}$ solved in $1 \mathrm{~mL}$ water was added dropwise. The reaction was aged for 3 hours in the ice bath. The reaction mixture was stirred for another hour before $70 \mathrm{mg} \mathrm{KPF}_{6}(0.38 \mathrm{mmol})$ was added. The aqueous phase of the mixture was removed. The organic phase was washed several times with with water and methanol. After about two weeks, cube-like black crystals were crystallized with the diffusion by hexane at $4{ }^{\circ} \mathrm{C}$ in a refrigerator. The yield of the crystals was $35 \%$.

Single crystal analysis. The diffraction data of $\mathrm{Ag}_{40} \mathrm{H}_{12}$ nanocluster was collected by X-ray single crystal diffractometer with Mo $\mathrm{K} \alpha$ radiation $(\lambda=0.71073 \AA)$ at $100 \mathrm{~K}$ on an Agilent Technologies SuperNova system. The data was processed using CrysAlis ${ }^{\text {Pro }}$. Cluster structure was solved and refined using Fullmatrix least-squares based on $\mathrm{F}^{2}$ with program ShelXT and ShelXL within Olex2. More detailed refinement data are provided in Table S3.

Physical Measurements. UV-vis absorption spectra were recorded on a Shimadzu UV-2550/2600 Spectrophotometer using a quartz cuvette of $1 \mathrm{~mm}$ path length. Mass spectra were recorded on an Agilent Technologies ESI-TOF-MS. TEM studies were performed on a TECNAI F-30 transmission electron microscope operating at $300 \mathrm{kV} .{ }^{2} \mathrm{H}-\mathrm{NMR}$ spectrum was recorded on an AVANCE III $850 \mathrm{MHz}$ spectrometer in dichloroethane/methanol. Chemical shifts are reported in ppm with internal TMS signal at 0.0 ppm as a standard.

Computational Details. The density functional theory (DFT) calculations were run as implemented in the GPAW package. ${ }^{43}$ The grid spacing of $0.20 \AA$ was used in real space, and the exchange and correlation effects were modeled using the PBE (PerdewBurke-Ernzerhof) functional. ${ }^{45}$ The initial structure for relaxation was obtained directly from the crystallographic data and the relaxation was stopped when the residual forces per atom were below $0.05 \mathrm{eV} / \AA$. The computational cell had $6 \AA$ of vacuum around the cluster. All calculations were done with charge state of $2+$. The Bader charge analysis was run on the total DFT electron density. ${ }^{46}$ The electronic structure of the clusters was studied by projecting the Kohn-Sham electronic wave functions to spherical symmetry and to $\mathrm{O}_{\mathrm{h}}$ symmetry group as described in refs. 38 and 45 , respectively.

The molecular dynamics (MD) simulations were run using Langevin dynamics with target temperature at $300 \mathrm{~K}$, friction parameter of $0.01 \mathrm{fs}^{-1}$ and time step of $2.0 \mathrm{fs}$. Simplified cluster models were considered in the MD simulations, where the real 2,4DMBT ligand used in the experiment was replaced by methylthiolate and the $\mathrm{PPh}_{3}$ was modeled with $\mathrm{P}\left(\mathrm{CH}_{3}\right)_{3}$. The masses of all hydrogen atoms were set to the mass of deuterium to slow down the $\mathrm{C}-\mathrm{H}$ bond vibrations allowing for a longer MD time step.

\section{ASSOCIATED CONTENT}

Supporting Information. More crystallographic structure analysis, NMR, temperature-dependent ESI-MS and UV-vis data (PDF).

Crystallographic structure and data of $\mathrm{Ag}_{40} \mathrm{H}_{12}$ (cif).

Videos of MD simulations of the $\mathrm{Ag}_{40}$ cluster with and without hydrides (mp4).

\section{AUTHOR INFORMATION}

Corresponding Author *nfzheng@xmu.edu.cn

*hannu.j.hakkinen@jyu.fi

Notes

The authors declare no competing financial interest.

\section{ACKNOWLEDGMENT}

We acknowledge the support from the National Key R\&D Program of China (2017YFA0207302), the National Natural Science Foundation of China $(21890752,21731005,21420102001$, and 21721001), the fundamental research funds for central universities (20720180026). The work in University of Jyväskylä was supported by the Academy of Finland (HH's Academy Professorship and grants 294217 and 319208). The computations were made at the CSC computing center in Espoo, Finland. $\mathrm{HH}$ acknowledges support from China's National Innovation and Intelligence Introduction Base visitor program.

\section{REFERENCES}

1. Yan, J. Z.; Teo, B. K.; Zheng, N. F., Surface Chemistry of Atomically Precise Coinage-Metal Nanoclusters: From Structural Control to Surface Reactivity and Catalysis. Acc. Chem. Res. 2018, 51, 3084-3093.

2. Jin, R. C.; Zeng, C.; Zhou, M.; Chen, Y., Atomically Precise Colloidal Metal Nanoclusters and Nanoparticles: Fundamentals and Opportunities. Chem. Rev. 2016, 116, 10346-10413.

3. Jadzinsky, P. D.; Calero, G.; Ackerson, C. J.; Bushnell, D. A.; Kornberg, R. D., Structure of a thiol monolayer-protected gold nanoparticle at 1.1 angstrom resolution. Science 2007, 318, 430-433.

4. Deng, H. J.; Wang, S. X.; Jin, S.; Yang, S.; Xu, Y. J.; Liu, L. L.; Xiang, J.; Hu, D. Q.; Zhu, M. Z., Active metal (cadmium) doping enhanced the stability of inert metal (gold) nanocluster under O-2 atmosphere and the catalysis activity of benzyl alcohol oxidation. Gold Bull 2015, 48, 161-167. 5. Urushizaki, M.; Kitazawa, H.; Takano, S.; Takahata, R.; Yamazoe, S.; Tsukuda, T., Synthesis and Catalytic Application of $\mathrm{Ag}_{44}$ Clusters Supported on Mesoporous Carbon. J. Phys. Chem. C 2015, 119, 2748327488.

6. Li, G.; Jin, R. C., Atomically Precise Gold Nanoclusters as New Model Catalysts. Acc. Chem. Res. 2013, 46, 1749-1758.

7. Ren, L. T.; Yuan, P.; Su, H. F.; Malola, S.; Lin, S. C.; Tang, Z. C.; Teo, B. K.; Hakkinen, H.; Zheng, L. S.; Zheng, N. F., Bulky Surface Ligands Promote Surface Reactivities of $\left[\mathrm{Ag}_{141} \mathrm{X}_{12}(\mathrm{~S}-\mathrm{Adm})_{40}\right]^{3+}(\mathrm{X}=\mathrm{Cl}, \mathrm{Br}, \mathrm{I})$ Nanoclusters: Models for Multiple-Twinned Nanoparticles. J. Am. Chem. Soc. 2017, 139, 13288-13291.

8. Tang, Q.; Lee, Y. J.; Li, D. Y.; Choi, W.; Liu, C. W.; Lee, D.; Jiang, D. E., Lattice-Hydride Mechanism in Electrocatalytic $\mathrm{CO}_{2}$ Reduction by Structurally Precise Copper-Hydride Nanoclusters. J. Am. Chem. Soc. 2017, 139, 9728-9736.

9. Yang, H. Y.; Wang, Y.; Huang, H.; Gell, L.; Lehtovaara, L.; Malola, S.; Hakkinen, H.; Zheng, N. F., All-thiol-stabilized $A g_{44}$ and $A_{12} A_{32}$ nanoparticles with single-crystal structures. Nat. Commun. 2013, 4, 2422.

10. Teo, B. K.; Zhang, H., Molecular Machines - Molecular-Structure of $\left[\left(p-\mathrm{Tol}_{3} \mathrm{P}\right)_{10} \mathrm{Au}_{13} \mathrm{Ag}_{12} \mathrm{Cl}_{8}\right]\left(\mathrm{PF}_{6}\right)$ - a Cluster with a Biicosahedral Rotor-Like Metal Core and an Unusual Arrangement of Bridging Ligands. Angew. Chem., Int. Ed. 1992, 31, 445-447.

11. Du, W. J.; Jin, S.; Xiong, L.; Chen, M.; Zhang, J.; Zou, X. J.; Pei, Y.; Wang, S. X.; Zhu, M. Z., $\mathrm{Ag}_{50}(\mathrm{Dppm})_{6}(\mathrm{SR})_{30}$ and Its Homologue $\mathrm{Au}_{\mathrm{x}} \mathrm{Ag}_{50-}$ x $(\mathrm{Dppm})_{6}(\mathrm{SR})_{30}$ Alloy Nanocluster: Seeded Growth, Structure Determination, and Differences in Properties. J. Am. Chem. Soc. 2017, 139, 1618-1624.

12. Zeng, J. L.; Guan, Z. J.; Du, Y.; Nan, Z. A.; Lin, Y. M.; Wang, Q. M., Chloride-Promoted Formation of a Bimetallic Nanocluster $\mathrm{Au}_{80} \mathrm{Ag}_{30}$ and the Total Structure Determination. J. Am. Chem. Soc. 2016, 138, 78487851.

13. Wu, Z. K.; Jin, R. C., Stability of the Two Au-S Binding Modes in $\mathrm{Au}_{25}(\mathrm{SG})_{18}$ Nanoclusters Probed by NMR and Optical Spectroscopy. ACS Nano. 2009, 3, 2036-2042.

14. Levi-Kalisman, Y.; Jadzinsky, P. D.; Kalisman, N.; Tsunoyama, H.; Tsukuda, T.; Bushnell, D. A.; Kornberg, R. D., Synthesis and Characterization of $\mathrm{Au}_{102}(p-\mathrm{MBA})_{44}$ Nanoparticles. J. Am. Chem. Soc. 2011, 133, 2976-2982.

15. Yan, N.; Xia, N.; Liao, L. W.; Zhu, M.; Jin, F. M.; Jin, R. C.; Wu, Z. K., Unraveling the long-pursued Au144 structure by x-ray crystallography. Sci. Adv. 2018, 4, eaat7259. 
16. Yang, H. Y.; Lei, J.; Wu, B. H.; Wang, Y.; Zhou, M.; Xia, A.; Zheng, L. S.; Zheng, N. F., Crystal structure of a luminescent thiolated Ag nanocluster with an octahedral $\mathrm{Ag}_{6}{ }^{4+}$ core. Chem. Commun. 2013, 49, 3002.

17. Joshi, C. P.; Bootharaju, M. S.; Alhilaly, M. J.; Bakr, O. M., $\left[\mathrm{Ag}_{25}(\mathrm{SR})_{18}\right]:$ The "Golden" Silver Nanoparticle. J. Am. Chem. Soc. 2015, $137,11578-11581$

18. AbdulHalim, L. G.; Bootharaju, M. S.; Tang, Q.; Del Gobbo, S.; AbdulHalim, R. G.; Eddaoudi, M.; Jiang, D. E.; Bakr, O. M., $\mathrm{Ag}_{29}(\mathrm{BDT})_{12}(\mathrm{TPP})_{4}$ : A Tetravalent Nanocluster. J. Am. Chem. Soc. 2015, 137, 11970-11975.

19. Nag, A.; Kovalenko, M. V.; Lee, J. S.; Liu, W. Y.; Spokoyny, B.; Talapin, D. V., Metal-free Inorganic Ligands for Colloidal Nanocrystals: $\mathrm{S}_{2}^{-}, \mathrm{HS}^{-}, \mathrm{Se}^{2-}, \mathrm{HSe}^{-}, \mathrm{Te}^{2-}, \mathrm{HTe}^{-}, \mathrm{TeS}_{3}{ }^{2-}, \mathrm{OH}^{-}$, and $\mathrm{NH}_{2}{ }^{-}$as Surface Ligands. J. Am. Chem. Soc. 2011, 133, 10612-10620.

20. Shimizu, K.; Sato, R.; Satsuma, A., Direct C-C Cross-Coupling of Secondary and Primary Alcohols Catalyzed by a gamma-AluminaSupported Silver Subnanocluster. Angew. Chem., Int. Ed. 2009, 48, 39823986.

21. Bootharaju, M. S.; Dey, R.; Gevers, L. E.; Hedhili, M. N.; Basset, J. M.; Bakr, O. M., A New Class of Atomically Precise, Hydride-Rich Silver Nanoclusters Co-Protected by Phosphines. J. Am. Chem. Soc. 2016, 1377013773

22. Dhayal, R. S.; Liao, J. H.; Wang, X. P.; Liu, Y. C.; Chiang, M. H.; Kahlal, S.; Saillard, J. Y.; Liu, C. W., Diselenophosphate-Induced Conversion of an Achiral $\left[\mathrm{Cu}_{20} \mathrm{H}_{11}\left\{\mathrm{~S} 2 \mathrm{P}(\mathrm{OiPr})_{2}\right\}_{9}\right]$ into a Chiral $\left[\mathrm{Cu}_{20 \mathrm{a}} \mathrm{H}_{11}\left\{\mathrm{Se}_{2} \mathrm{P}(\mathrm{OiPr})_{2}\right\}_{9}\right]$ Polyhydrido Nanocluster. Angew. Chem., Int. Ed. 2015, 54, 13604-13608.

23. Edwards, A. J.; Dhayal, R. S.; Liao, P. K.; Liao, J. H.; Chiang, M. H.; Piltz, R. O.; Kahlal, S.; Saillard, J. Y.; Liu, C. W., Chinese Puzzle Molecule: A 15 Hydride, 28 Copper Atom Nanoball. Angew. Chem. Int. Ed. 2014, 53, 7214-7218.

24. Dhayal, R. S.; Liao, J. H.; Kahlal, S.; Wang, X. P.; Liu, Y. C.; Chiang, M. H.; van Zyl, W. E.; Saillard, J. Y.; Liu, C. W., $\left[\mathrm{Cu}_{32}(\mathrm{H})_{20}\left\{\mathrm{~S}_{2} \mathrm{P}(\mathrm{OiPr})_{2}\right\}_{12}\right]$ : The Largest Number of Hydrides Recorded in a Molecular Nanocluster by Neutron Diffraction. Chem. Eur. J. 2015, 21, 8369-8374.

25. Sun, C. F.; Mammen, N.; Kaappa, S.; Yuan, P.; Deng, G. C.; Zhao, C. W.; Yan, J. Z.; Malola, S.; Honkala, K.; Hakkinen, H.; Teo, B. K.; Zheng, N. F., Atomically Precise, Thiolated Copper-Hydride Nanoclusters as Single-Site Hydrogenation Catalysts for Ketones in Mild Conditions. Acs. Nano. 2019, 5975-5986.

26. Liu, C. W.; Lin, Y. R.; Fang, C. S.; Latouche, C.; Kahlal, S.; Saillard, J. $\mathrm{Y}$., $\left[\mathrm{Ag}_{7}(\mathrm{H})\left\{\mathrm{E}_{2} \mathrm{P}(\mathrm{OR})_{2}\right\}_{6}\right](\mathrm{E}=\mathrm{Se}, \mathrm{S})$ : precursors for the fabrication of silver nanoparticles. Inorg. Chem. 2013, 52, 2070-2077.

27. Liu, C. W.; Chang, H. W.; Fang, C. S.; Sarkar, B.; Wang, J. C., Aniontemplated syntheses of octanuclear silver clusters from a silver dithiophosphate chain. Chem. Commun. 2010, 46, 4571-4573.

28. Liu, C. W.; Liao, P. K.; Fang, C. S.; Saillard, J. Y.; Kahlal, S.; Wang, J. C., An eleven-vertex deltahedron with hexacapped trigonal bipyramidal geometry. Chem. Commun. 2011, 47, 5831-5833.

29. Liu, C. W.; Chang, H. W.; Sarkar, B.; Saillard, J. Y.; Kahlal, S.; Wu, Y. Y., Stable silver(I) hydride complexes supported by diselenophosphate ligands. Inorg. Chem. 2010, 49, 468-475.

30. Zavras, A.; Ariafard, A.; Khairallah, G. N.; White, J. M.; Mulder, R. J.; Canty, A. J.; O'Hair, R. A., Synthesis, structure and gas-phase reactivity of the mixed silver hydride borohydride nanocluster $\left[\operatorname{Ag}_{3}\left(\mu_{3}-\mathrm{H}\right)\left(\mu_{3^{-}}\right.\right.$ $\left.\left.\mathrm{BH}_{4}\right) \mathrm{L}^{\mathrm{Ph} 3}\right] \mathrm{BF}_{4}\left(\mathrm{~L}^{\mathrm{Ph}}=\right.$ bis(diphenylphosphino)methane). Nanoscale 2015, 7, $18129-18137$

31. Ma, H. Z.; White, J. M.; Mulder, R. J.; Reid, G. E.; Canty, A. J.; O'Hair, R. A. J., Synthesis, structure, and condensed-phase reactivity of $\left[\mathrm{Ag}_{3}\left(\mu_{3-}\right.\right.$
$\left.\mathrm{H})\left(\mu_{3}-\mathrm{BH}_{4}\right) \mathrm{L}^{\mathrm{Ph} 3}\right]\left(\mathrm{BF}_{4}\right) \quad\left(\mathrm{L}^{\mathrm{Ph}}=\right.$ bis(diphenylphosphino)amine) with $\mathrm{CS}_{2}$. Dalton Trans. 2018, 47, 14713-14725.

32. Cook, A. W.; Nguyen, T. D.; Buratto, W. R.; Wu, G.; Hayton, T. W., Synthesis, Characterization, and Reactivity of the Group 11 Hydrido Clusters $\left[\mathrm{Ag}_{6} \mathrm{H}_{4}(\mathrm{dppm})_{4}(\mathrm{OAc})_{2}\right]$ and $\left[\mathrm{Cu}_{3} \mathrm{H}(\mathrm{dppm})_{3}(\mathrm{OAc})_{2}\right]$. Inorg. Chem. 2016, $55,12435-12440$.

33. Tate, B. K.; Wyss, C. M.; Bacsa, J.; Kluge, K.; Gelbaum, L.; Sadighi, J. P., A dinuclear silver hydride and an umpolung reaction of $\mathrm{CO}_{2}$. Chem. Sci. 2013, 4, 3068-3074.

34. Teller, R. G.; Bau, R. In Crystallographic studies of transition metal hydride complexes, Metal Complexes, Berlin, Heidelberg, 1981//; Bau, R.; Gütlich, P.; Teller, R. G., Eds. Springer Berlin Heidelberg: Berlin, Heidelberg, 1981; pp 1-82.

35. Zavras, A.; Khairallah, G. N.; Connell, T. U.; White, J. M.; Edwards, A. J.; Donnelly, P. S.; O'Hair, R. A., Synthesis, structure and gas-phase reactivity of a silver hydride complex $\left[\mathrm{Ag}_{3}\left\{\left(\mathrm{PPh}_{2}\right)_{2} \mathrm{CH}_{2}\right\}_{3}\left(\mu_{3}-\mathrm{H}\right)\left(\mu_{3}-\right.\right.$ Cl)] $\mathrm{BF}_{4}$. Angew. Chem., Int. Ed. 2013, 52, 8391-8394.

36. Chai, J. S.; Yang, S.; Lv, Y.; Chen, T.; Wang, S. X.; Yu, H. Z.; Zhu, M. Z., A Unique Pair: $\mathrm{Ag}_{40}$ and $\mathrm{Ag}_{46}$ Nanoclusters with the Same Surface but Different Cores for Structure-Property Correlation. J. Am. Chem. Soc. 2018, 140, 15582-15585.

37. Bodiuzzaman, M.; Ghosh, A.; Sugi, K. S.; Nag, A.; Khatun, E.; Varghese, B.; Paramasivam, G.; Antharjanam, S.; Natarajan, G.; Pradeep, T., Camouflaging Structural Diversity: Co-crystallization of Two Different Nanoparticles Having Different Cores But the Same Shell. Angew. Chem., Int. Ed. 2019, 58, 189-194.

38. Walter, M.; Akola, J.; Lopez-Acevedo, O.; Jadzinsky, P. D.; Calero, G.; Ackerson, C. J.; Whetten, R. L.; Gronbeck, H.; Häkkinen, H., A unified view of ligand-protected gold clusters as superatom complexes. Proc. Natl. Acad. Sci. USA 2008, 105, 9157-9162.

39. Joshi, C. P.; Bootharaju, M. S.; Bakr, O. M., Tuning Properties in Silver Clusters. J. Phys. Chem. Lett. 2015, 6, 3023-3035.

40. Cook, A. W.; Hayton, T. W., Case Studies in Nanocluster Synthesis and Characterization: Challenges and Opportunities. Acc. Chem. Res. 2018, 51, 2456-2464.

41. Dhayal, R. S.; Liao, J. H.; Lin, Y. R.; Liao, P. K.; Kahlal, S.; Saillard, J. Y.; Liu, C. W., A Nanospheric Polyhydrido Copper Cluster of Elongated Triangular Orthobicupola Array: Liberation of $\mathrm{H}_{2}$ from Solar Energy. $J$. Am. Chem. Soc. 2013, 135, 4704-4707.

42. Dhayal, R. S.; van Zyl, W. E.; Liu, C. W., Polyhydrido Copper Clusters: Synthetic Advances, Structural Diversity, and Nanocluster-to-Nanoparticle Conversion. Acc. Chem. Res. 2016, 49, 86-95.

43. Enkovaara, J.; Rostgaard, C.; Mortensen, J. J.; Chen, J.; Dulak, M.; Ferrighi, L.; Gavnholt, J.; Glinsvad, C.; Haikola, V.; Hansen, H. A.; Kristoffersen, H. H.; Kuisma, M.; Larsen, A. H.; Lehtovaara, L.; Ljungberg, M.; Lopez-Acevedo, O.; Moses, P. G.; Ojanen, J.; Olsen, T.; Petzold, V.; Romero, N. A.; Stausholm-Moller, J.; Strange, M.; Tritsaris, G. A.; Vanin, M.; Walter, M.; Hammer, B.; Hakkinen, H.; Madsen, G. K.; Nieminen, R. M.; Norskov, J. K.; Puska, M.; Rantala, T. T.; Schiotz, J.; Thygesen, K. S.; Jacobsen, K. W., Electronic structure calculations with GPAW: a real-space implementation of the projector augmented-wave method. J. Phys. Condens. Matter. 2010, 22, 253202.

44. Kaappa, S.; Malola, S.; Hakkinen, H., Point Group Symmetry Analysis of the Electronic Structure of Bare and Protected Metal Nanocrystals. $J$. Phys. Chem. A 2018, 122, 8576-8584.

45. Perdew, J. P.; Burke, K.; Ernzerhof, M., Generalized gradient approximation made simple. Phys. Rev. Lett. 1996, 77, 3865-3868. 46. Tang, W.; Sanville, E.; Henkelman, G., A grid-based Bader analysis algorithm without lattice bias. J. Phys. Condens. Matter. 2009, 21, 084204. 
1

2

3

5

5

6

7

8

9

10

11

12

13

14

15

16

17

18

19

20

21

22

23

24

25

26

27

28

29

30

31

32

33

34

35

36

37

38

39

40

41

42

43

44

45

46

47

48

49

50

51

52

53

54

55

56

57

58

59

60
TOC

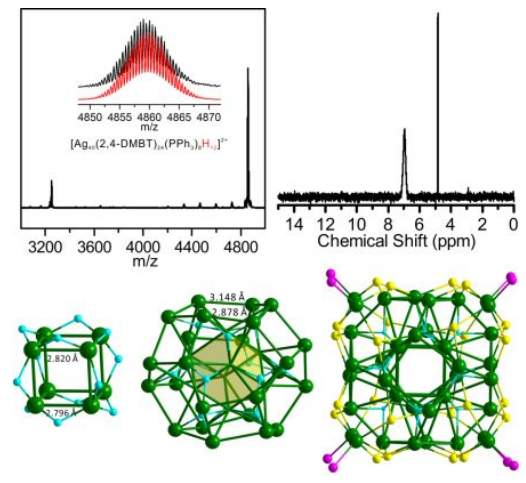

ACS Paragon Plus Environment 